
\title{
$\angle S$ Research Suare \\ Production of Gas Diffusion Layers with Cotton Fibers for its use in Fuel Cells
}

\section{A. Navarro}

Polytechnic University of Cartagena

\section{Gómez}

Polytechnic University of Cartagena

L. Daza

Instituto de Catálisis y Petroquímica CSIC

J. J. Lopez-Cascales ( $\boldsymbol{\nabla}$ javier.lopez@upct.es )

Polytechnic University of Cartagena

\section{Research Article}

Keywords: gas diffusion layer (GDL), proton exchange membrane fuel cell (PEMFC) , catalyst surface,membrane electrode assembling (MEA)

Posted Date: October 25th, 2021

DOI: https://doi.org/10.21203/rs.3.rs-1007793/v1

License: (1) (1) This work is licensed under a Creative Commons Attribution 4.0 International License. Read Full License 


\title{
Production of Gas Diffusion Layers with cotton fibers for its use in Fuel Cells
}

\author{
A.J. Navarro' ${ }^{1}$ M.A. Gómez ${ }^{1}$, L. Daza ${ }^{2}$, and J.J. López-Cascales ${ }^{1, *}$ \\ ${ }^{1}$ Universidad Politécnica de Cartagena, Dep. Ing. Quimica y Ambiental, Campus Alfonso XIII, Aulario C, \\ Cartagena 30203, Murcia, Spain \\ ${ }^{2}$ Instituto de Catálisis y Petroquímica, C/ Marie Curie 2, Campus Cantoblanco 28049 Madrid, Spain. \\ *To whom correspondence should be addressed: javier.lopez@upct.es
}

\begin{abstract}
The gas diffusion layer (GDL) plays an important role in a proton exchange membrane fuel cell (PEMFC) transporting the current to the collector plates, distributing the reactant gases to the catalyst surface, and evacuating the heat and water that is generated during the redox reactions. Speaking in terms of production cost, the GDL represents between $30 \%$ and $50 \%$ of the total cost of the membrane electrode assembling (MEA). However, despite its importance in fuel cells, until recent years, the GDLs have not been studied with the same intensity than other MEA components, such as the catalyst or the proton membrane.

In this work, we present the production process of a low cost GDL family that was developed at laboratory scale, using a non-woven paper-making process. A relevant aspect of these GDLs is that $40 \%$ of their composition is natural cotton, despite which they present good electrical and thermal conductivity, high porosity, good pore morphology, high hydrophobicity and gas permeability. Furthermore, when the GDL with its optimum cotton content was tested in a single open cathode fuel cell, a good performance was obtained, that make of this GDL a promising candidate for its use in fuel cells.
\end{abstract}

\section{Introduction.}

During the last decades, hydrogen fuel cells have received a growing interest for their use in a wide variety of stationary and mobile applications. That interest is mainly due to the increasing concern about environmental problems in general, and the stress associated with the turbulent market of the fossil fuels ${ }^{1,2}$.

In this context, fuel cells are electrochemical devices in which the electrical power is produced by the hydrogen oxidation and oxygen reduction, generating only water and heat in the process ${ }^{3-5}$.

Among other types of fuel cells, the proton exchange membrane fuel cell (PEMFC) is the most widely used, because they employ a solid and stable electrolyte, they provide high current densities, they request a short starting time and they keep a reasonable long lifetime $e^{4,6,7}$.

In this context, the gas diffusion layer (GDL) constitutes one of the main components at the heart of the fuel cells, together with the catalyst and proton membrane ${ }^{4}$. Among other functions, GDLs play a crucial role collecting the electrons generated in the electrochemical reaction, distributing the reactant gases to the catalyst surface, and evacuating the water and heat generated inside the fuel cell during the electrochemical reactions ${ }^{8,9}$.

However and despite of those important roles played by the GDLs, for years a relative low attention has been paid to this fuel cell component, compared to the effort put on the developing of new catalysts and proton membranes ${ }^{4}$. Fortunately, that trend changed during the last years. Thus, for example, Lin et $\mathrm{al}^{10}$ focused their effort on the effect of the presence of carbon nanotubes in the micro porous layer on the performance of a proton exchange membrane fuel cell. Chen et al. ${ }^{11}$ optimized the interface between the microporous layer and the electrolyte membrane with decorative patterns. Indayaningsih et al. ${ }^{12}$ produced new gas diffusion layers using carbon coconut fibers as main ingredient for their preparation. Chen et $\mathrm{al}^{13}$ and $\mathrm{Ji}$ et $\mathrm{al}^{14}$ performed studies on the role played by the microporous layer on water management in a proton membrane fuel cell. Ferreira-Aparicion et al. ${ }^{15}$ studied the effect of the gas diffusion cathode structure on the performance of an air breathing proton exchange membrane fuel cell. Kim et al. ${ }^{16}$ studied the effect of the crack in a gas diffusion layer on the performance of a fuel cell. Zenyuk et al. ${ }^{17}$ and Oualid et al ${ }^{18}$ studied the effect of clamp pressure on the structure of a gas diffusion layer and its effect on the fuel cell performance. Yang et al. ${ }^{19}$ studied the use of graphene oxide reinforced ultra thin carbon paper for fabricating gas diffusion layers. Lee et $\mathrm{al}^{20}$ proposed the employ of an improved single layer as gas diffusion layer in a fuel cell after graphene incorporation to its composition. Tabe et $\mathrm{al}^{21}$ studied the impact of the micro porous layer morphology and on the liquid water distribution at the catalyst interface and how this affect to the fuel cell performance. In line with this study, Chen et $\mathrm{al}^{22}$ investigated the effect of PTFE on the water transport in gas diffusion layer. Fadzillah et $\mathrm{al}^{23}$ modeled the 
microstructure of a gas diffusion layer and analyzed the effect of hydrophobicity, thickness, porosity and fiber diameter on the fuel cell performance. In this context, a type of GDL that is widely used in fuel cells is based on non-woven carbon paper, in which different components such as carbon nanotubes and cellulose fibers coated with conducting polymers, have been added to the carbon paper during its fabrication to improve its electrical conductivity and permeability ${ }^{24-28}$.

In this work we present a novel preparing method of gas diffusion layer in which renewable cotton cellulose is used in its fabrication. Furthermore, these GDLs were subsequently characterized and its performance studied in a single fuel cell.

\section{Experimental.}

\subsection{GDL preparation}

The GDLs are usually composed of two different layers: the MPS (Macro Porous Substrate) and the MPL (Micro Porous Layer). Thus, the MPS provides mechanical support to the GDL and excellent electrical conductivity and gas permeability, meanwhile the MPL with its micro porosity, facilitates the gas distribution to the active sites on the catalyst surface ${ }^{4,9,29}$.

The MPS was prepared with the following materials: carbon fibers of 3mm length (CF) (SGL-carbon), natural cotton fibers (CC), graphite powder (GP)( Merk), commercial polyamide epoxy (PE), Poly(tetrafluoroethylene) (PTFE) in aqueous solution $60 \mathrm{wt} \%$ (Alfa Aeser) and acetylene carbon black (AC) (Alfa Aesar).

After several trials and attendant error, the final recipe for fabricating the MPS was as follows: $1.8 \mathrm{~g} \mathrm{CF}, 1.1 \mathrm{~g}$ GP and $6 \mathrm{ml}$ PE. Thus, maintaining the quantities of these components constant, the cotton fiber was varied from 0.5 to $2 \mathrm{~g}$, which represents a change from $14 \%$ to $40 \%$ of the total mass. Now, all those components were mixed in $1 \mathrm{~L}$ of water, and stirred for 20 minutes until a homogeneous suspension was obtained. This suspension was then filtered in a $170 \mathrm{~mm}$ diameter Büchner funnel. The paste obtained after filtration was compacted with a pressure of $18 \mathrm{~kg} / \mathrm{cm}^{2}$. Then, the paste was baked for 14 hours at $300{ }^{\circ} \mathrm{C}$, followed by 25 minutes at $1000{ }^{\circ} \mathrm{C}$. At the end of this process, a MPS of $0.30 \pm 0.05 \mathrm{~mm}$ thick was obtained.
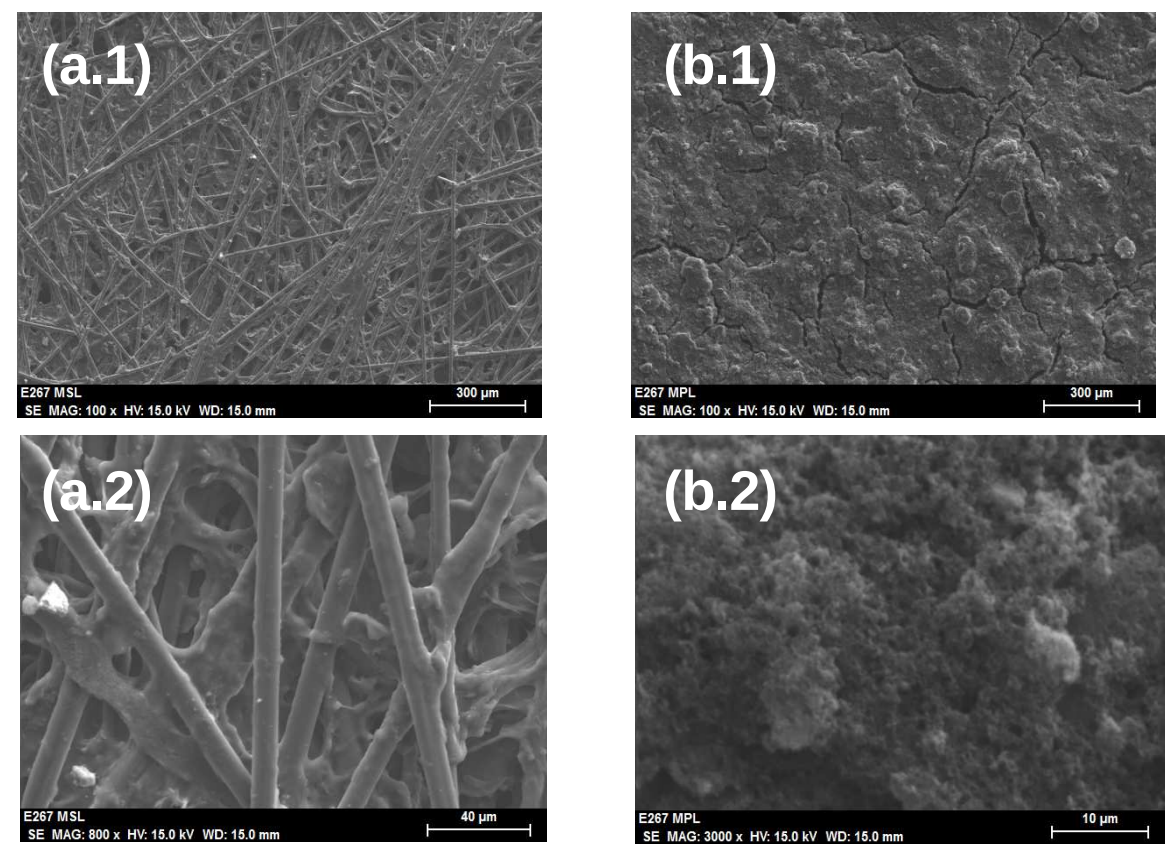

Figure 1. SEM images of the MPS (a.1 and a.2) and MPL (b.1 and b.2) synthesized in this work with a $40 \%$ in cotton fiber content.

The micro porous layer (MPL) was generated by spray deposition of a solution containing $0.5 \mathrm{~g}$ carbon black in $100 \mathrm{ml}$ of 2-isopropanol. This carbon solution was deposited on the MPS until a surface concentration of $1.7 \mathrm{mg} / \mathrm{cm}^{2}$ carbon black was obtained. This process generated a micro porous layer of around $0.12 \mathrm{~mm}$ thickness. Thus, considering the MPS+MPL, a GDL of $0.42 \pm 0.05 \mathrm{~mm}$ was generated. 
Figure 1 shows the morphology of the MPS and MPL generated following the procedure described above. Note that the small slits on their surface are similar to those seen in the MPLs of other manufacturers ${ }^{25,30}$, due to the stress generated during the solvent evaporation.

To increase the hydrophobicity of the GDL, it was sprayed on by aerography with $10 \mathrm{ml}$ of a solution of 2-isopropanol containing PTFE, until the MPL was coated with a $25 \%$ PTFE, for an optimal response of the GDL in a fuel cell ${ }^{31}$.

\subsection{Electrode preparation.}

The electroactive electrodes were prepared by painting a thin-film of catalyst on the proton membrane of Nafion NR-212 (IonPower) using the electrospray technique $\mathrm{e}^{32-35}$. Thus, an ink containing $0.04 \mathrm{~g}$ of $20 \% \mathrm{Pt}$ on graphitized carbon (Sigma-Aldrich), and $0.002 \mathrm{~g}$ of $5 \%$ Nafion solution (Alfa-Aesar), which represents the $25 \%$ of the catalyst in weight, was prepared. Both, Pt/C and Nafion were mixed in $40 \mathrm{ml}$ of 2-isopropanol, and subjected to ultrasound for 1 hour and stirred for 24 hours before use. After the ink was ready, the catalyst was deposited on the membrane till obtaining a concentration of $0.2 \mathrm{mgPt} / \mathrm{cm}^{2}$.

\subsection{Single fuel Cell}

The fuel cell used for testing the GDLs was a single open cathode fuel cell (OC-PEMFC), and the plates used for the fuel cell assembling were manufactured in our university using 304 stainless steel. Later, both plates were covered with a very thin layer of gold to improve their electrical conductivity and electrochemical stability. The anode was designed considering parallel channels of $2 \mathrm{~mm}$ width and $1 \mathrm{~mm}$ depth, with $1 \mathrm{~mm}$ rib width, while the cathode was designed by parallel channels of $2 \mathrm{~mm}$ width, $3 \mathrm{~mm}$ depth, and $1 \mathrm{~mm}$ rib width. In this fuel cell, the cathode was open to the air, and oxygen was blown to the fuel cell by means of an external fan, coupled to the fuel cell. To prevent the proton membrane from drying, the cathode channels were maintained parallel to the table surface, and the fan speed was controlled electronically as a function of the current demanded. Temperature was initially fixed at $40{ }^{0} \mathrm{C}$, and hydrogen was used directly from the bottle without humidification, with a dead back pressure of 1 bar. The air temperature and air $\mathrm{RH}$ was maintained at $30{ }^{0} \mathrm{C}$ and $50-55 \% \mathrm{RH}$ by means of a standard air conditioning unit. The active surface area of this single fuel cell was $23.1 \mathrm{~cm}^{2}$.

\section{Results and Discussion}

\subsection{Electrical conductivity}

The gas diffusion layer is an anisotropic system due to the different orientation of its components in- and through- the plane. Hence, two different values of electrical conductivity have to be specified to characterize the electrical conductivity of a GDL.

The electrical conductivity in the plane was measured using the linear four points method, employing a distance between two consecutive points of $5 \mathrm{~mm}$. This method consists in determining the potential difference between two points due to the application of an electrical current between the other two, where the distance between consecutive points was maintained constant $^{36,37}$. Thus, the electrical resistivity in the plane can be measured as follows ${ }^{36}$ :

$$
\rho_{\text {in }}=\frac{\pi t}{\ln 2} \frac{V}{I}
$$

where $\mathrm{t}$ is the sample thickness, I the electrical current applied between the two external points and V the electrical potential measured between the other two points. Hence, the electrical conductivity, $\sigma_{\text {in }}$, can be obtained as follows,

$$
\sigma_{i n}=\frac{1}{\rho}
$$

where $\sigma_{\text {in }}$ is expressed in $S / m$.

In this regard, Figure 2 shows the variation in the electrical conductivity of the GDLs with different cotton content.

Figure 2 shows how increasing the percentage of cotton from 14\% to 32\% reduces the electrical conductivity of the GDL. This result was expected, since cotton fibers acts as an electrical insulator. However, this trend changed sharply when the cotton content reached $40 \%$ of the GDL composition. We associated this change in trend to the fact that for $40 \%$ of cotton in the GDL composition, more graphite and carbon fibers were trapped between adjacent cotton fibers during the filtration process in the MPS fabrication, resulting as a consequence, an increase in the electrical conductivity of the GDL.

Thus, the value of the electrical conductivity of the GDL with a $40 \%$ in cotton is in the same order of magnitude than the value of $\sigma_{i n}=4421 \pm 160 \mathrm{~S} / \mathrm{m}$ measured by Ozden et $\mathrm{al}^{4}$ for the commercial Sigracet 38BC.

The through-plane electrical resistivity, $\rho_{T}$, it was obtained from the following equation $3\left({ }^{38}\right)$ :

$$
R_{T}=\frac{\rho_{T} \cdot l}{A}
$$




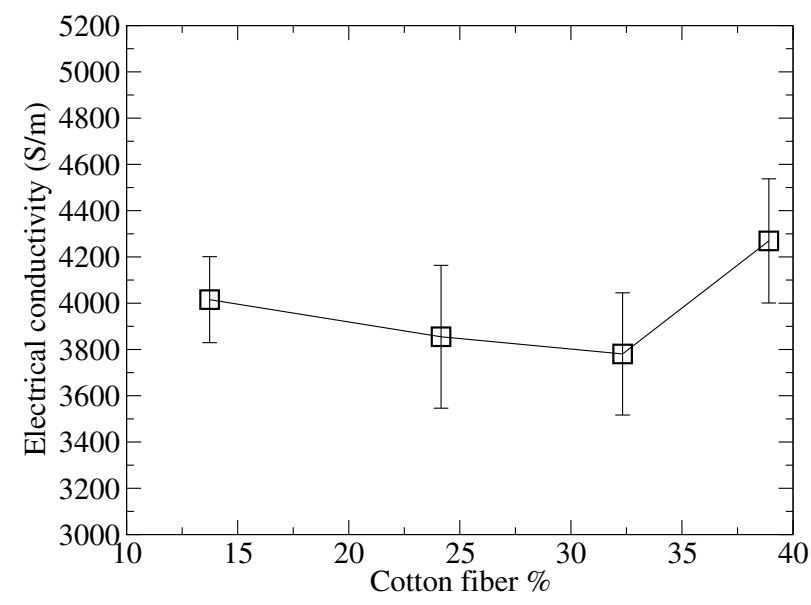

Figure 2. In plane electrical conductivity of the GDLs with different percentages of cotton fiber.

where $R_{T}$ is the electrical resistance of a sample confined between two copper plates with a golden bath, under a pressure of $10 \mathrm{~kg} / \mathrm{cm}^{2}$ and measured with a miniOhmeter BK-Precision BA6010 at $1 \mathrm{kHz}, \rho_{T}$ is the resistivity expressed as $\frac{O \mathrm{Ohms. \textrm {cm } ^ { 2 }}}{\mathrm{cm}}, A$ is the transversal surface, and $l$ the sample thickness. Thus, the through plane conductivity, $\sigma_{T}$, corresponds to the inverse of $\rho_{T}, \sigma_{T}=\frac{1}{\rho_{T}}$, and its units are $S / \mathrm{cm}$. Figure 3 shows the transversal electrical conductivity of the GDLs with different cotton content.

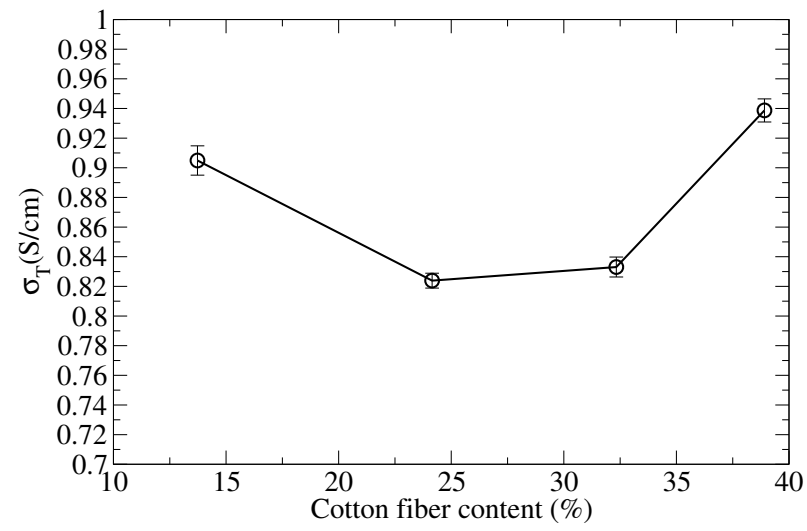

Figure 3. Through plane electrical conductivity of the GDLs with different percentages of cotton content.

Figure 3 shows as the transversal electrical conductivity follows the same trend than the in-plane electrical conductivity. Thus, an increase in the cotton content produces a diminishing in the transversal electrical conductivity till reaching critical value, where beyond that point, the electrical conductivity rise up. The explication of this behavior is in line with the used for explaining the behavior of the in-plane electrical conductivity, in the sense that beyond a certain critical cotton content, an increase in the number of electrical contacts through the plane is expected as a consequence of resulting more graphite and carbon fibers trapped between the cotton fibers, and hence, an increase of the electrical conductivity through the plane is expected. Those values measured for our GDLs are typically a $50 \%$ of the value measured for the Sigracet $38 \mathrm{BC}$, where 
$2.00 \pm 0.04 \mathrm{~S} / \mathrm{cm}$ has been measured.

\subsection{Porosity and hydrophobicity.}

Porosity and hydrophobicity provide information on the ease with which gases can penetrate into the GDL and how the GDL deals with the water during the electrochemical reactions inside the fuel cell. To measure the porosity of the different GDLs, in a first instance, the pycnometer method was used, in which kerosene (Sigma-Aldrich) served as the solvent for the porosity determination. The porosity $\varepsilon$ of a composting mass is defined as the ratio between the void volume of the sample $\left(V_{v}\right)$ and the total volume of sample $\left(V_{s}\right)$, including air. Thus, the porosity $\varepsilon$ was measured as follows ${ }^{39}$ :

$$
\varepsilon=\frac{V_{v}}{V_{s}}
$$

where $V_{v}$ is determined using kerosene as solvent at $25{ }^{\circ} \mathrm{C}$, and $V_{s}$ is the macroscopic volume of the sample. Figure 4 shows how the porosity of the GDL increases with the cotton fiber content. But this trend is broken when cotton reached a $40 \%$ content.

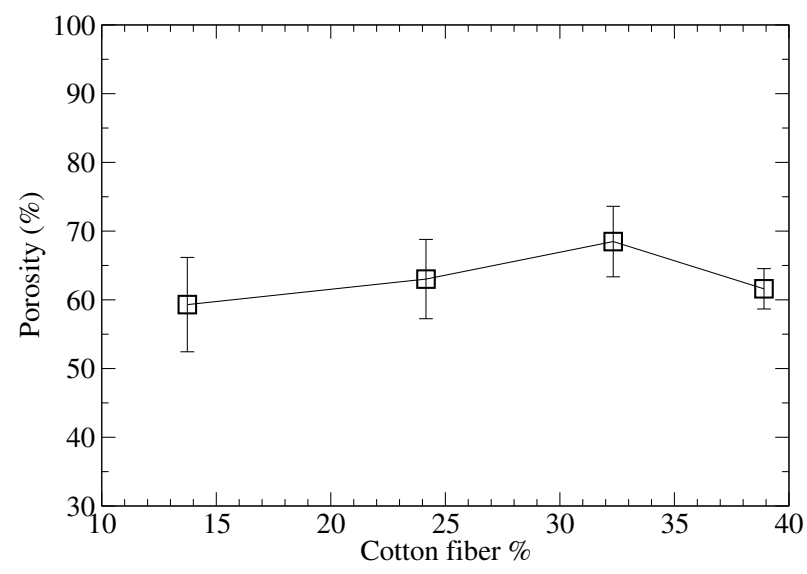

Figure 4. Porosity of the GDLs depending on the cotton fiber content.

This behavior is explained on the fact that cotton fibers have a branched structure which increases the empty space of the GDL due to fiber overlaps. This result is in a perfect agreement with the electrical conductivity measured above, in which the GDL with a $40 \%$ cotton content showed the highest conductivity due to the fact that more graphite powder is trapped between the fibers that form the MPS, and as a consequence, the electrical conductivity increases i.e. its porosity diminishes, in a perfect correlation between both properties. In general, all our GDLs showed a porosity in a range from 60 to $67 \%$.

With the objective of gathering further information about the morphology of those GDLs, the pore distribution and porosity of the GDL with $40 \%$ cotton content was studied with the mercury porosimetry technique. Thus, its porosity and macro porous distribution was determined using an intrusion-extrusion mercury porosimeter Autopore IV 9510 of the Institute of catalyst and Petrochemical, CSIC, Madrid. For the pore size determination, the volume of mercury that penetrated into the sample was measured as a function of the pressure applied. Equation 5 corresponding to the Washburn equation for cylindrical pores, was the equation applied for obtaining the pore size distribution, $\mathrm{d}$ :

$$
d=-\frac{4 \sigma \cos \theta}{p}
$$

where $\theta$ and $\sigma$ correspond to the contact angle and surface tension, that for mercury $\theta=130^{0}$, and $\sigma=485$ dyn.cm ${ }^{-1}$.

Figure 5 shows a mono-modal distribution for our GDL with maximum at $28000 \mathrm{~nm}$ that contrasts with the bimodal distribution of the Sigracet 38BC with two peaks at 1384 and $78000 \mathrm{~nm}$, with an average pore diameter (4V/A) of $1916 \mathrm{~nm}$ for our GDL against 442,4 $\mathrm{nm}$ for the Sigracet 38BC. This enhancement in the pore diameter is of crucial importance for the 


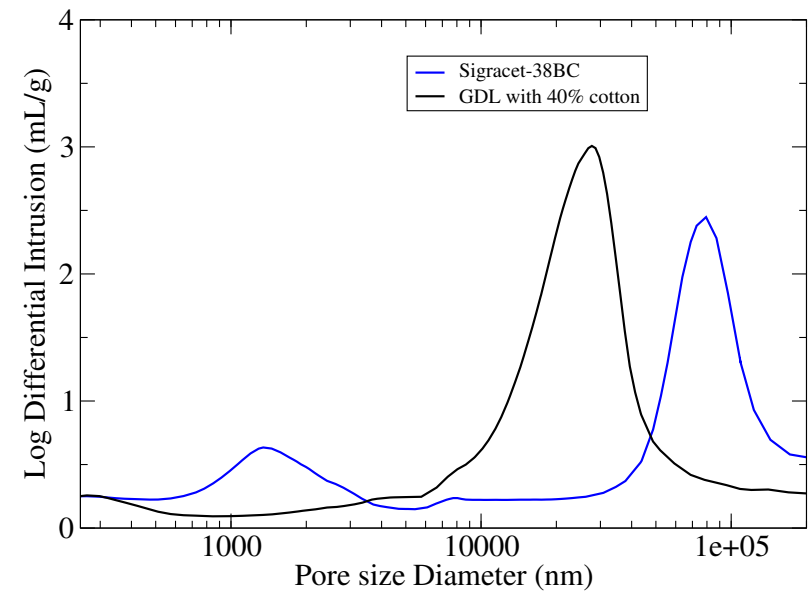

Figure 5. Pore distribution of the GDL with a 40\% cotton content and Sigracet 38BC.

\begin{tabular}{|c|c|c|}
\hline Property & GDl 40\% cotton & Sigracet 38BC \\
\hline Porosity $(\%)$ & 71.786 & 74.27 \\
\hline Pore area $(59917 \mathrm{psia}) \mathrm{m}^{2} / \mathrm{g}$ & 3.889 & 16.664 \\
\hline Pore diameter $(4 \mathrm{~V} / \mathrm{A})(\mathrm{nm})$ & 1916.2 & 442,4 \\
\hline
\end{tabular}

Table 1. Porosity, pore area and pore diameter determined by mercury porosimetry.

water managing in the interior of the fuel cells, since pore diameter is involved in the water condensation process according to the Young-Laplace equation.

Furthermore, Table 1 shows a summary of the most relevant parameters of our GDl with $40 \%$ cotton content and Sigracet 38BC.

From the results of Table 1, we observe that in general, Sigracet 38BC presents a porosity slightly higher than our GDL with a $40 \%$ cotton content. Thus, Sigracet $38 \mathrm{BC}$ shows a $74.27 \%$ of porosity that agrees with the $80 \%$ of porosity indicated in its technical data sheet ${ }^{40}$, against the $71.782 \%$ of our GDL. In our case, the porosity measured using the mercury porosimetry technique is roughly a $15 \%$ higher than the values obtained using the pycnometer method described above.

Thus, hydrophobicity together with the porosity of the GDLs (properties that are related each other ${ }^{41}$ ) are two key properties for managing the water generated in a fuel cell ${ }^{30}$. An estimation of the contact angle of a water droplet of 30 micro-liters with the MPL was carried out, obtaining angles of 170 and 152 degrees for our GDL with $40 \%$ cotton content and Sigracet $38 \mathrm{BC}$, respectively. This diminishing in the contact angle on the Sigracet 38BC is associated with a reduction of the hydrophobicity in comparison with our GDL fabricated with cotton fibers.

\subsection{Air permeability.}

An important property associated with the GDL performance is its permeability to gases. In this regard, and although this property is in part related with its porosity, this is only partially true because the permeability is mainly associated with the morphology of the pore structure, while porosity is related to the void volume available inside the GDL. In our case, the permeability was measured using the Gürley method, such as it is described in the UNE Norm 57066-2:2003. The surface area through which air is forced to pass through was $6.45 \mathrm{~cm}^{2}$.

Figure 6 shows how the permeability to air increases with the cotton content, fitting this trend to a straight line. Such behavior is probably due to the fact that when more natural fibers there is in a GL, the greater the number of connections between neighboring pores and hence, the permeability to gases increases. Given that permeability measured for the Sigracet$38 \mathrm{BC}$ was $1.2 \mathrm{~cm} / \mathrm{s}$, our cotton GDLs showed a much higher air permeability than the Sigracet grade, with an increase of roughly a $80 \%$ respect to Sigracet-38BC. 


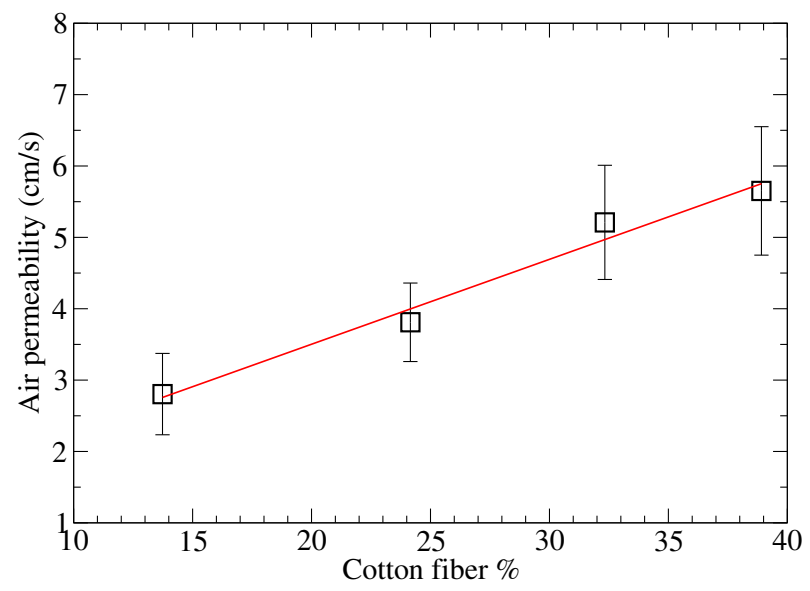

Figure 6. GDL permeability as a function of the cotton fiber content using the Gürley method.

\subsection{Thermal conductivity, $\kappa$}

The thermal conductivity, $\kappa$, was measured on the assumption that a flat thin surface divides two fluids (air) at different temperature. Thus, under this premise, the thermal conductivity can be measured using a home-made chamber that is controlled electronically with Arduino (Arduino trademark, www.arduino.cc), where $T_{1}^{f}$ corresponds to the temperature of the fluid (air) outside of the chamber, $T_{1}^{S}$ is the temperature at the outlet face of the GDL, $T_{2}^{S}$ is the temperature at the inlet face of the GDL, $T_{2}^{f}$ is the temperature of air inside the chamber, and $\mathrm{b}$ the GDL thickness.

Thus, in an stationary regime, we can write:

$$
q=\frac{\phi}{S}=h_{1}\left(T_{1}^{f}-T_{1}^{S}\right) \longrightarrow T_{1}^{f}-T_{1}^{S}=\frac{q}{h_{1}}=\frac{1}{h_{1}} \frac{\phi}{S}
$$

In a stationary state, this power will be transmitted by conduction through the wall,

$$
q=\frac{\lambda}{b}\left(T_{1}^{S}-T_{2}^{S}\right) \longrightarrow T_{1}^{S}-T_{2}^{S}=\frac{b}{\kappa} q
$$

and the same quantity from the surface $S_{2}$ to the cold fluid,

$$
q=h_{2}\left(T_{2}^{S}-T_{1}^{S}\right) \longrightarrow T_{2}^{S}-T_{2}^{f}=\frac{q}{h_{2}}
$$

Thus, by combining the equations 7 and 8 , the following expression is obtained:

$$
\kappa=\frac{b \cdot\left(T_{2}^{S}-T_{2}^{f}\right) \cdot h}{\left(T_{1}^{S}-T_{2}^{S}\right)}
$$

where the thermal conductivity $\kappa$ can be obtained from the measurement of four temperatures: the temperatures corresponding to the inside and out side of the isolated chamber, and the temperatures on both faces of the sample (GDL). Finally, $\mathrm{h}$ is a parameter that must be fitted using a substance of reference. In our case, we used as standard a piece of glass of $2 \mathrm{~mm}$ thick, where $1.4 \frac{\mathrm{W}}{\mathrm{K} . m}$ was considered as the reference thermal conductivity ${ }^{42}$. To verify this procedure, the thermal conductivity of a piece of polypropylene film of $0.5 \mathrm{~mm}$ thick was measured, obtaining a value of $0.193 \pm 0.004 \frac{\mathrm{W}}{\mathrm{K} . \mathrm{m}}$ at $30{ }^{0} \mathrm{C}$, that is in perfect agreement with the reported data, which range from 0.17 to $0.22 \frac{\mathrm{W}}{K . m} 43,44$

After calibration, the thermal conductivity of the GDL with $40 \%$ cotton was measured as a function of the temperature, since this GDL was the GDL that showed the best electrical conductivity and permeability to gases, making it the most suitable 


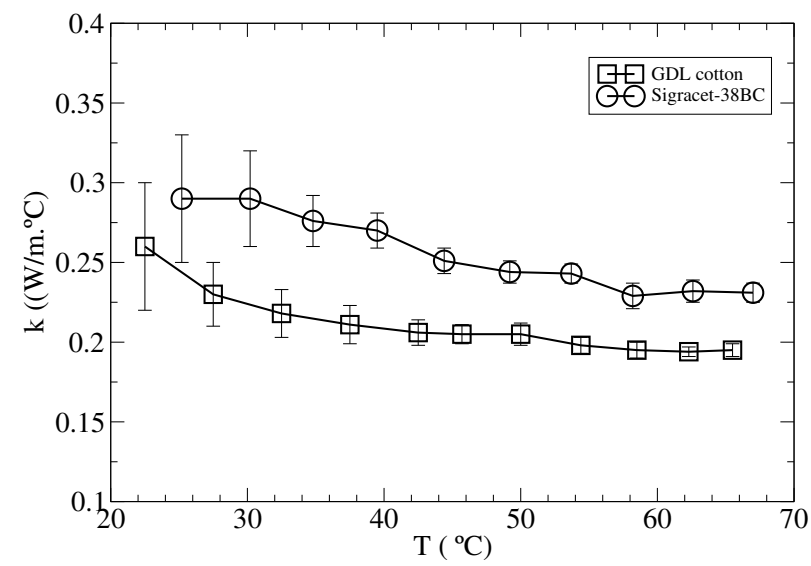

Figure 7. Thermal conductivity of a GDL with $40 \%$ cotton fiber content and Sigracet 38BC, as a function of temperature.

candidate for its use in the fuel cell. Figure 7 shows the variation of $\kappa$ for our GDL with a $40 \%$ fiber content and Sigracet $38 \mathrm{BC}$, as a function of temperature.

Looking at Figure 7, we see as Sigracet 38BC shows higher thermal conductivity than our GDL for the whole range of temperatures studied. For temperatures below 40 degree Celsius, Sigracet 38BC showed a thermal conductivity around 30\% higher than the GDL with cotton. This difference is reduced to $20 \%$ for temperatures above 50 degree Celsius.

Thus, a value of $\kappa=0.195 \pm 0.006 \frac{W}{K . m}$ and $0.229 \pm 0.008 \frac{W}{K . m}$ was measured at $58{ }^{0} C$ for the GDL with cotton and Sigracet-38BC, respectively, which are in the same order of magnitude than the values of $\kappa$ reported for different Sigracet grades which ranged from $0.22 \pm 0.04$ to $0.31 \pm 0.06 \frac{W}{K . m} 45$.

\subsection{Fuel Cell Behavior: Polarization curves.}

Figure 8 shows two polarization curves corresponding to the single open cathode fuel cell with the GDL with $40 \%$ of cotton fibers, and the Sigracet 38BC. The polarization curves were generated using an electronic DC Load 3721A of Array Electronic Co., Ltd. (http://www.array.sh/).

Figure 8 shows the polarization curves at $40{ }^{\circ} \mathrm{C}$ obtained after 7 days since activation, working at a constant current density of $0.2 \mathrm{~A} / \mathrm{cm}^{2}$ during that time. To prevent an excess of water accumulation in the anode, hydrogen was purged every 30 minutes, with a purge time of $0.2 \mathrm{~s}$. Figure 8 shows how our GDL with $40 \%$ of cotton provides similar performance to Sigracet 38BC.

The relation between cell potential and current density has been shown that obey to the following equation ${ }^{46}$,

$$
E=E_{0}-b \log i-R . i
$$

where,

$$
E_{0}=E_{r}-b \log i_{0}
$$

being $E_{r}$ the reversible potential, $i_{0}$ the exchange current, $b$ the Taeffel's slope and $\mathrm{R}$ the lineal resistance that gather the contribution of the proton membrane and hardware Ohmic resistance. Table 2 shows the fitting parameters of the two polarization curves.

Thus, Table 2 shows how the fuel cell with Sigracet 38BC presents lower Ohmic resistance than the fuel cell with GDLs with Cotton. Based on the fact that both fuel cells were fabricated with the same type of proton membrane, and that both electrodes were fabricated using the same procedure and catalyst content, we can assume that the increase in a $20 \%$ in the Ohmic resistance can be associated with the increase in the transversal resistance of our GDL with $40 \%$ cotton content in comparison with Sigracet 38BC, such as we discussed above. Furthermore, this result agrees with the average internal resistance measured during the generation of the polarization curves, with values of 24 and $9 \mathrm{~m} \Omega$ for the GDL with $40 \%$ cotton and Sigracet 38BC, respectively. 


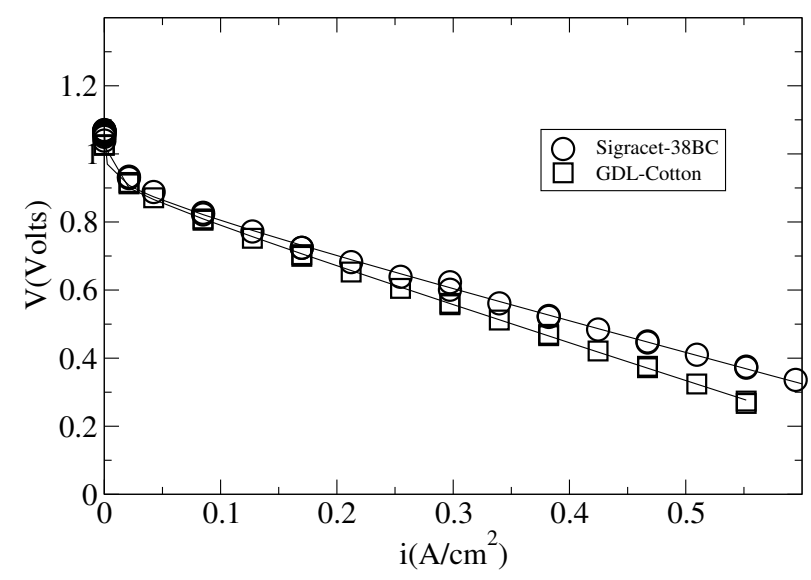

Figure 8. Polarization curves. Solid lines correspond to the fitting using the equation 10

\begin{tabular}{|c|c|c|c|}
\hline GDL & $E_{0}(\mathrm{~V})$ & $b\left(\right.$ V.dec $\left.^{-1}\right)$ & $R\left(\Omega . \mathrm{cm}^{2}\right)$ \\
\hline 38BC & 0.84 & 0.049 & 0.88 \\
\hline Cotton & 0.86 & 0.037 & 1.07 \\
\hline
\end{tabular}

Table 2. Fitting parameters of both polarization curves of Figure 8 attending equation 2.

On the other sort of things, from both polarization curves of Figure 8, we don't see any over potential associated with mass diffusion of reactant gases, or water flooding effect.

\section{Conclusions.}

During recent decades, hydrogen has become a plausible alternative to fossil fuels, because when hydrogen is used in a fuel cell, we are able to produce electrical current, heat and water, without emitting polluting gases.

The Gas Diffusion Layer (GDL) is one of the main components at the heart of the PEMFC. One of the main problems that constrain the greater use of fuel cells in a much wider number of stationary and mobile applications, is associated with the cost of the key components of these electrochemical devices: the catalyst, the proton membrane and the gas diffusion layer, where the GDL represents between 30\% and $50 \%$ of the total cost of a MEA fabrication, depending of the catalyst content.

In this work, we present for first time, a new family of GDL made with a high content of renewable material, in our case, natural cotton fiber. Furthermore, these GDLs are produced using an environmental friendly method in which water was used as solvent for preparing carbon paper instead of polluting and hazardous organic solvents.

Thus, the ex-situ study of the electric conductivity, porosity, permeability and thermal conductivity, showed that these GDLs behave as the commercial GDLs, although further studies have to be carried our to reduce their trough-plane electrical resistance for improving its response in a fuel cell.

\section{Acknowledgment}

The authors acknowledge the foresight to the Universidad Politécnica de Cartagena for providing a new laboratory for hydrogen research. AJN thanks the Universidad Politecnica de Cartagena for awarding a grant of Iniciación a la Investigación financed by the Santander Bank. AJN and MAG are actually working on this project with a contract funded by the Comunidad Atonoma de la Region de Murcia, Conserjeria de Desarrollo Económico, Turismo y Empleo, and the European Union, through the program RIS3MUR with Ref:2I20SAE00079. 


\section{References}

1. Busby, R. L. Hydrogen and fuel cells (Pennwell Publishing, 2005).

2. Srinivasan, S. Fuel cells: From fundamentals to applications. (Springer, 2007).

3. Litster, S. \& McLean, G. Pem fuel cell electrodes. J. Power Sources 120, 61-76 (2004).

4. Ozden, A., Shahgaldi, S., Li, X. \& Hamdullahpur, F. A review of gas diffusion layers for proton exchange membrane fuel cell-with a focus on characteristics, characterization techniques, materials and designs. Prog. Energy Combust. Sci. 74, 50-102 (2019).

5. Spiegel, C. S. Designing and Building Fuel Cells (McGrawHill, 2007).

6. Borup, R. et al. Scientific aspects of polymer electrolyte fuel cell durability and degradation. Chem. Rev. 107, 3904-3951 (2007).

7. Cheng, X. et al. A review of pem hydrogen fuel cell contamination. impacts, mechanisms and mitigation. J. Power Sources 165, 739-756 (2007).

8. H.Li et al. A review of water flooding issues in the proton exchange membrane fuel cell. J. Power Sources 178, 103-117 (2008).

9. El-Kharouf, A., Rees, N. \& Steinberger-Wilckens, R. Gas diffusion layer materials and their effect on polymer electrolyte fuel cell performance- ex situ and in situ characterization. Fuel Cells 14, 735-741 (2014).

10. Lin, R. et al. Detailed optimization of multiwall carbon nanotubes doped microporous layer in polymer electrolyte membrane fuel cells for enhanced performance. Appl. Energy 274, 115214 (2020).

11. Chen, L. et al. Microporous layers with different decorative pattern for polymer electrolyte membrane fuel cells. Appl. Mater. Interfaces 12, 24048-24058 (2020).

12. Indayaningsih, N., Zulfia, A., Priadi, D. \& Hendrana, S. Preparation if carbon composites from coconut fiber for gas diffusion layer. Ionics 22, 1445-1449 (2016).

13. Chen, G., Zhang, G., Guo, L. \& Liu, H. Systematic study on the function and mechanism of micro porous layer on water transport in proton exchange membrane fuel cell. Int. J. Hydrog. Energy 41, 5063-5073 (2016).

14. Ji, M. \& Wei, Z. A review of water management in polymer electrolyte membrane fuel cell. Energies 2, 1057-1106 (2009).

15. Ferreira-Aparicio, P. \& Chaparro, A. Influence of the gas diffusion cathode structure on the performance of an airbreathing proton exchange membrane fuel cell. Int. J. Hydrog. Energy 39, 3997-4004 (2014).

16. Kim, G., Kim, D., Kim, J., Kim, H. \& Park, T. Impact of cracked gas diffusion layer on performance of polymer electrolyte membrane fuel cells. J. Ind. Eng. Chem. 91, 311-316 (2020).

17. Zenyuk, I., Parkinson, D. Y., Connolly, L. \& Weber, A. Gas-diffusion-layer properties under compression via x-ray tomography. J. Power Sources 328, 364-376 (2016).

18. Oualid, S., Lachat, R., Candusso, D. \& Meyer, Y. Characterization process to measure the electrical contact of gas diffusion layers under mechanical static compressive loads. Int. J. Hydrog. Energy 42, 23920-23931 (2017).

19. Yang, P., Xie, Z., Li, H., Wang, P. \& Huang, Q. Graphene oxide reinforced ultra-thin carbon paper used for fuel cells and the mechanism of reinforcement. Int. J. Hydrog. Energy 42, 11699-11709 (2017).

20. Lee, H., Chang, J. \& Chen-Yang, Y. Improvement in physical properties of single-layer gas diffusion layers using graphene for proton exchange membrane fuel cells. RSC Adv. 8, 22506-22514 (2018).

21. Tabe, Y., Aoyama, Y., Kadowaki, K., Suzuki, K. \& Chikahisa, T. Impact of micro-porous layer on liquid water distribution at the catalyst layer interface and cell performance in a polymer electrolyte membrane fuel cell. J. Power Sources 287, 422-430 (2015).

22. Chen, Y. et al. Influence of ptfe on water transport in gas diffusion layer of polymer electrolyte membrane fuel cell. Int. J. Electrochem. Sci. 13, 3827-3842 (2018).

23. Fadzillah, D., Rosli, M., Talib, M., Kamarudin, S. \& Daud, W. Review on microstructure modelling of a gas diffusion layer for proton exchange membrane fuel cells. Renew. sustainable Energy Rev. 77, 1001-1009 (2017).

24. Mathur, R., Maheshwari, P., Dhami, T., Sharma, R. \& Sharma, C. Processing of carbon composite papers as electrode for fuel cell. J. Power Sources 161, 790-798 (2006). 
25. Isikel, L., Gocek, I. \& Adanur, S. Design and characterization of nonwoven fabrics for gas diffusion layer in polymer electrolyte membrane fuel cell. The J. The Text. Inst. 101, 1006-1014 (2010).

26. Jabbour, L., Chaussy, D., Eyraud, B. \& Beneventi, D. Highly conductive graphite/carbon fiber/celulose composite papers. Compos. Sci. Technol. 72, 616-623 (2012).

27. Maheshwari, P., Gupta, C. \& Mathur, R. Role of fiber length and pore former on the porous network of carbon paper electrode and its performance in pemfc. Fuel Cells 14, 566-753 (2014).

28. Shi, Y. \& Wang, B. Mechanical properties of carbon fiber/cellulose composite papers modified by hot-melting fibers. Prog. Nat. Sci. Mater. Int. 24, 56-60 (2014).

29. El-Kharouf, A., Mason, T., Brett, D. \& Pollet, B. Ex-situ characterisation of gas diffusion layers for proton exchange membrane fuel cells. J. Power Sources 218, 393-404 (2012).

30. Lapicque, F., Belhadj, M., Bonnet, C., Pauchet, J. \& Thomas, Y. A critical review on gas diffusion micro and macroporous layers degradations for improved membrane fuel cell durability. J. Power Sources 336, 40-53 (2016).

31. Xiong, Z. et al. Enhanced water management in the cathode of an air-breathing pemfc using a dual catalyst layer and optimizing the gas diffusion and microporous layers. Int. J. Hydrog. Energy 40, 3961-3967 (2015).

32. Varea, A., Monereo, O., Xuriguera, E., Prades, J. \& Cirera, A. Electrospray as a suitable technique for manufacturing carbon-based devices. J. Phys. D: Appl. Phys. 50, 315301-315311 (2017).

33. Castillo, J., Martin, S., D.Rodriguez-Perez, Higuera, F. \& Garcia-Ybarra, P. Nanostructured porous coating via electrospray atomization and deposition of nanoparticle suspensions. J. Aerosol Sci. 125, 148-163 (2018).

34. Bodnar, E., Grifoll, J. \& Rosell-Llompar, J. Polymer solution electrospraying: A tool for enineering particles and films with controlled morphology. J. Aerosol Sci. 125, 93-118 (2018).

35. Yan, J. et al. Highly conductives graphene paper with verically aligned reduces graphene oxide sheets fabricated by improved electrospray deposition technique. Applayd Mater. Interfaces 11, 10810-10817 (2019).

36. Miccoli, I., Edler, F., Pfnür, H. \& Tegenkamp, C. The 100th anniversary of the four-point probe technique: the role of probe geometries in isotropic and anisotropic systems. J. Phys.: Condens. Matter 27, 223201-223230 (2015).

37. Alarifi, I. Investigation the conductivity of carbon fiber composites focusing on measurement techniques under dynamic and static loads. J. Mater. Res. Technol. 8, 4863-4893 (2019).

38. Cooper, K. Characterizing throgh-plane and in-plane ionic conductivity of polymer electrolyte membranes. ECS Transaction 41, 1371-1380 (2011).

39. Ruggieri, L., Gea, T., Artola, A. \& Sánchez, A. Air filled porosity measurements by air pycnometry in the composting process: A review and a correlation analysis. Bioresour. Technol. 100, 2655-2666 (2009).

40. Carbon, S. Technical data sheet. Tech. Rep. URL https://www. fuelcellstore.com/fuel-cell-components/carbon

41. Cassie, A. \& Baxter, S. Wettability of porous surfaces. Faraday Soc. 40, 546-551 (1944).

42. Lide, D. R. CRC Handbook of Chemistry and Physics (CRC Press, 2007).

43. Birley, A., Heath, R. \& Scott, M. Plastic materials. Properties and applications (Springer, 1991).

44. Maier, C. \& Calafut, T. Polypropylene. The definitive user's guide and databookk (Elsevier Science, 1998).

45. Kandelwal, M. \& Mench, M. Direct measurement of through-plane thermal conductivity and contact resistence in fuel cell materials. J. Power Sources 161, 1106-1115 (2006).

46. Kim, J., Lee, S. \& Srinivasan, S. Modeling of proton exchange membrane fuel cell performance with an empirical equation. J. Electrochem. Soc. 142, 2670-2674 (1995).

\section{Conflict of interest}

Authors do not present any conflict of interest related with this work.

\section{Author contribution}

AJN presented an active participation in the synthesis of the GDLs. MAG was involved in the measurements of the different properties studied in this work. LD measured the properties related with the GDL porosity of the samples. JJLC coordinated the different tasks carried out in this work and wrote this manuscript. 